\title{
Patterns of lung and heart growth as determined from serial radiographs of 76 children with cystic fibrosis
}

\author{
MARGARET B. MEAR NS and G. SIMON \\ The Queen Elizabeth Hospital for Children, London E2 and Institute of Diseases of the Chest, London SW3
}

\begin{abstract}
Mearns, M. B., and Simon, G. (1973). Thorax, 28, 537-546. Patterns of lung and heart growth as determined from serial radiographs of 76 children with cystic fibrosis. Chest radiographs of 76 children with cystic fibrosis were taken each year to determine lung length, lung width, and heart diameter. These measurements were plotted on standard charts against age and studied in relation to the initial clinical status. The changes in the pattern of growth which occurred during a follow-up period of 4 to 9 years (average 7 years) were considered in relation to clinical changes and change in ventilatory capacity.

It was found that at 6 years of age the majority of patients had a lung width greater and heart diameter smaller than might have been expected. During the follow-up a decrease in lung width occurred without a proportionate increase in lung length. The lateral view radiographs did not show flattening of the diaphragm, and in the majority no other changes were found which would suggest marked overdistension of the lungs or increase in AP diameter.

One group of patients was found not to be increasing vital capacity with increasing height, although they did not demonstrate the clinical findings usually associated with progression of the pulmonary infection in cystic fibrosis. The lung measurement showed a greater decrease in lung width and more marked narrowing of the heart shadow than occurred in the other patients, irrespective of the progression of the pulmonary involvement. The significance of these findings has not been determined.
\end{abstract}

Standards of radiologically determined lung length, lung width, and heart diameter are available (Simon et al., 1972). A uniform method of assessing the radiological change in a series of patients with chronic pulmonary disease, such as cystic fibrosis, may be useful in correlating clinical and physiological changes. There have been many descriptions of the gross radiological findings in this disease and it has been frequently stated that there is generalized emphysema, narrowing of the cardiac shadow, and depression of the diaphragm (Neuhauser, 1946 ; Keats, 1955 ; White and Rowley, 1964). In the clinical assessment of these patients, many do not develop barrel-shaped chests although on measurement of the ratio of forced expired volume in one second to forced vital capacity $\left(F_{1}: F V C\right)$ there may be evidence of airways obstruction. The present study was undertaken to determine if by radiological measurement a pattern of disturbed growth could be identified and perhaps be related to the clinical course of the disease.

\section{MATERIAL}

Seventy-six of the 270 children with cystic fibrosis seen at the Queen Elizabeth Hospital since 1950 had had a minimum of four years follow-up after 6 years of age ; only 7 of the 76 were older than 6 years when they were first referred. These 76 patients $(40$ boys and 36 girls) are the subjects of the present study. The diagnosis of cystic fibrosis was confirmed in all these patients by finding the sweat sodium to be greater than $70 \mathrm{mEq} / \mathrm{l}$.

From 1964, FVC and FEV 1 were measured at least every three months at the routine clinic visit. Fiftynine of these 76 patients had serial tests over a minimum period of four years.

Chest radiographs were taken six-monthly but more frequently if clinically indicated. Lateral view radiographs were not taken unless specifically indicated but were available for 46 of the 76 patients at the final assessment.

Most of the patients when first studied were 6 years of age and were placed on the basis of clinical and radiological findings into three groups:

Group I (40 patients) good general health, no persistent cough or sputum. Chest radiograph 
normal or minimal thickened bronchial wall pattern (tram-line shadows)

Group II (25 patients) good general health. May have persistently purulent sputum, localized change on chest radiograph

Group III (11 patients) persistent pulmonary infection with purulent sputum; generalized changes in the chest radiograph

\section{METHOD}

Height was measured regularly throughout the study and plotted on height centile charts against age (Tanner, Whitehouse, and Takaishi, 1966).

Chest radiographs at approximately yearly intervals were measured and plotted on the lung centile charts against age, as described by Simon et al. (1973). The measurements made were the lung width, the lung length, and the transverse diameter of the heart shadow. For details of the method of measuring and the difficulties of assessing the accuracy and significance of the measurements, see Simon et al. (1972). The lung width: lung length ratio was calculated at 8 years and 12 years.

Lateral view radiographs in 46 cases were examined and assessed for the position and curve of the diaphragm, the size of the retrosternal transradiant zone, and the configuration of the sternum and spine.

Ventilatory capacity, forced vital capacity, and forced expiratory volume at one second were measured using a spirometer similar to that described by Bernstein, D'Silva, and Mendel (1952).

Since radiological measurements on the lung centile charts are related to age and not to height, for the purpose of this study it was assumed that in a normal child the height, the lung length, and the lung width centiles would be similar, i.e., a child whose height was on the $25^{\circ}$ centile might have lung length and lung width on or near the $25^{\circ}$ centiles for that age. A second assumption was made that the heart diameter centile might be expected to be similar to the lung length centile. In assessing heart size radiologically, lung length is more important than lung width only in patients with very long lungs (personal communication, Simon).

Four aspects were studied:

1 initial survey of the 76 patients. The centiles for height and radiological measurements were compared with each other and related to clinical grouping ;

2 change in height and lung measurements in each patient in the follow-up period of 4 to 9 years (average 7 years);

3 relation between change in ventilatory capacity, clinical status, and radiographic lung measurements ;

4 assessment of lateral view radiographs.

\section{RESULTS}

INITIAL SURVEY OF THE 76 PATIENTS

HEIGHT Forty-five per cent of the patients had a height centile on the $50^{\circ}$ or above and more girls than boys attained these upper centiles (Fig. 1). A similar distribution of the range of height was found when the 76 patients were considered -together or when group I was compared with groups II and III combined together (Table I). This suggested that at the age of 6 years height might be relatively independent of the severity of the pulmonary involvement. Although the heights may not have a normal distribution, the patients were not severely dwarfed and the more severely affected were not necessarily the smallest.

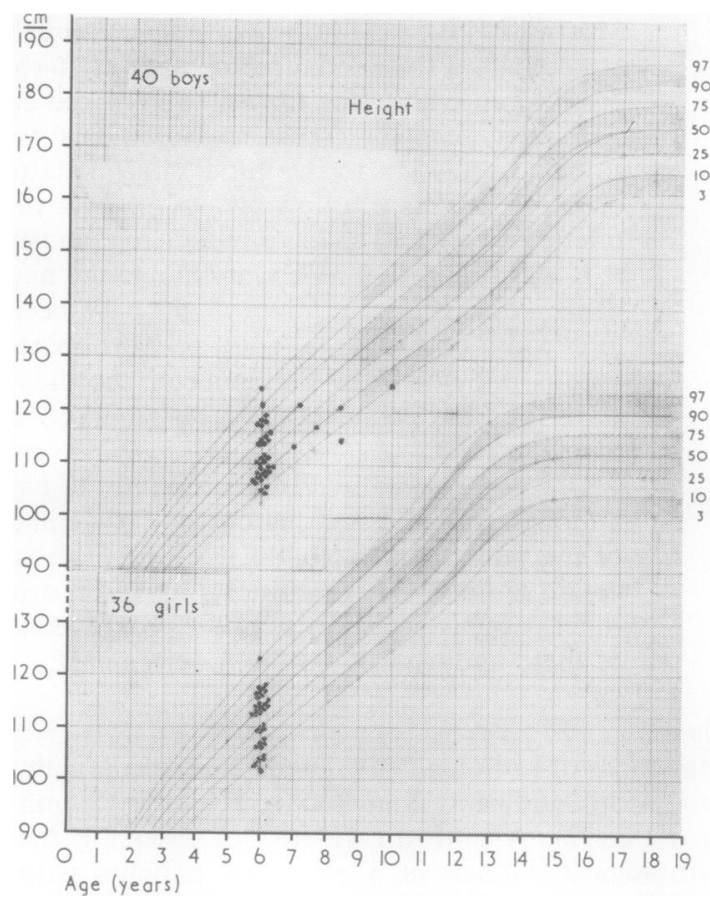

FIG. 1. Heights of the 76 patients at the beginning of the study plotted on height centile charts.

T A B L E I

HEIGHT RELATED TO CLINICAL GRADING

\begin{tabular}{c|c|c|c}
\hline Centile & $\begin{array}{c}\text { All Patients } \\
(\% \text { of 76) }\end{array}$ & $\begin{array}{c}\text { Group I } \\
(\% \text { of 40) }\end{array}$ & $\begin{array}{c}\text { Groups II and III } \\
(\% \text { of 36) }\end{array}$ \\
\hline $\begin{array}{c}75^{\circ} \text { and } \\
\text { above } \\
\text { on 50 } \\
10^{\circ} \text { or less }\end{array}$ & $22 \cdot 5$ & 25 & $19 \cdot 5$ \\
\hline
\end{tabular}

\section{RADIOGRAPHIC MEASUREMENTS}

The distribution in shown in Figure 2.

Lung length Thirty-five per cent of the patients had lung lengths greater than might have been 
expected from comparison with the height centile ; in $21 \%$ it was less.

Lung width In $61 \%$ of the patients the lung width was greater than might have been expected and in only $12 \%$ was it less.

Heart diameter In $50 \%$ of the patients this centile was less than might have been expected from comparison with the lung length centile, and in $26 \%$ it was greater.

Lung length: lung width ratio At 8 years this has been calculated to be between 0.8 and 0.82 in normal children (Simon et al., 1972). In these 76 patients the ratio was greater than 0.9 in $10 \%$ and less than 0.8 in $53 \%$.

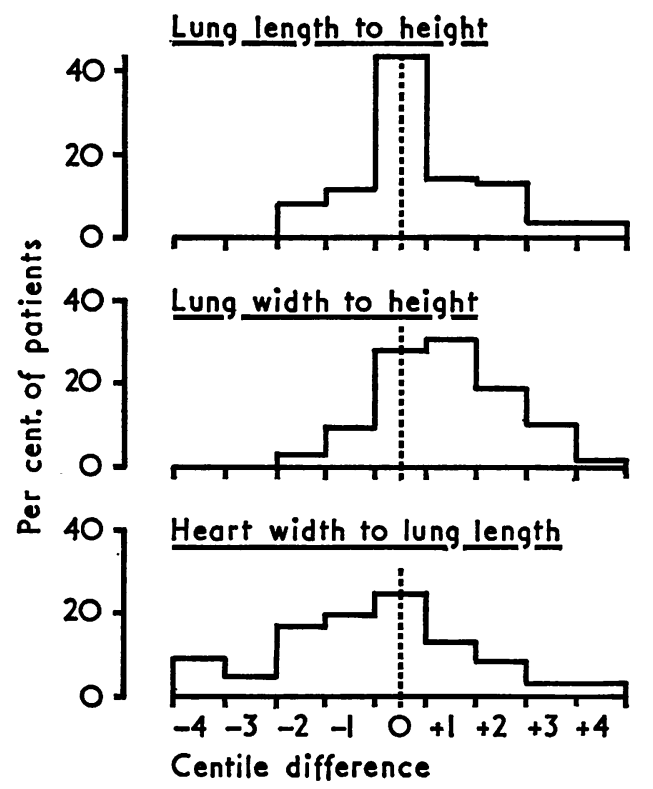

FIG. 2. Initial radiographic lung measurements. Differences in the centiles, height to lung length and lung width, and heart width to lung length expressed as (+) or $(-)$.

COMPARISON BETWEEN 40 PATIENTS IN GROUP I AND 11 PATIENTS IN GROUP III (Fig. 3)

Lung length Of group I $27 \%$ and of group III $82 \%$ of patients had lung length greater than the height centile. In group I height and lung length centiles were the same in $40 \%$ of the patients.

Lung width The same proportion of patients in groups I and III (62.5\% and $63 \%$ respectively) had wider lungs than might have been expected, but there was a trend for the lungs to become narrower in group III.

Heart diameter Fifty per cent of group I and $73 \%$ of group III patients had narrower heart diameter centiles in comparison with the lung length centiles. In approximately the same proportion of patients in groups I and III $(22.5 \%$ and $18 \%$ respectively) the heart diameter and lung length centiles were the same.

From the initial measurements at 6 years the patients with cystic fibrosis had a lung width greater and a heart diameter smaller than might have been expected if the two assumptions made previously are correct. The lung length centile tended to increase with the severity of the pulmonary involvement but the heart diameter centile when compared with the lung length was less than might have been expected. The lung width showed less correlation with the pulmonary changes.

CHANGE IN HEIGHT AND IN RADIOGRAPHIC LUNG MEASUREMENTS DURING A FOLLOW-UP STUDY 4-9 YEARS (AVERAGE 7 YEARS)

The change in the measurements which occurred have been assessed as shift from the initial centile line, i.e., an increase from one centile line to the next is expressed as +1 and a corresponding decrease as -1 , and no change as zero (0).

HEIGHT Fifty-one of 76 patients $(67 \%)$ stayed on the same centile throughout the study, in 12 patients there was an increase of one height centile, 11 patients decreased by one centile, and 2 patients with severe involvement decreased by 2 height centiles, but progressive pulmonary involvement was not always associated with a slowing of height increase.

\section{RADIOGRAPHIC MEASUREMENTS}

The distribution is shown in Figure 4.

Lung length Forty-nine per cent of the patients had no change in centile and equal proportions showed either an increase or decrease in lung length centile ( $26 \%$ and $25 \%$ respectively).

Lung width Twenty-five per cent of the patients had no change in centile but $65 \%$ showed a decrease in width centile.

Heart diameter Sixty-two per cent of the patients showed no change. Twenty-five per cent decreased this centile compared with $13 \%$ showing an increase. 


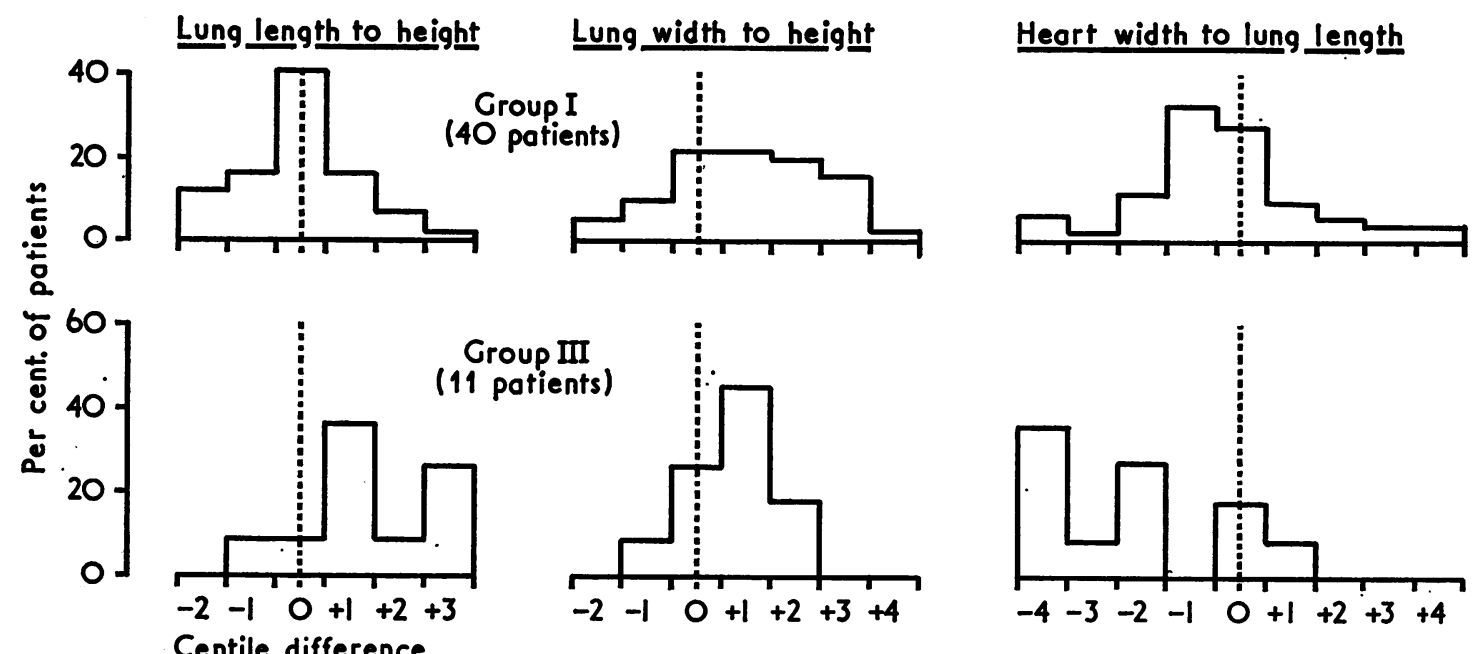

FIG. 3. Radiographic lung measurements compared in group I and group III patients (expressed as in Fig. 2).

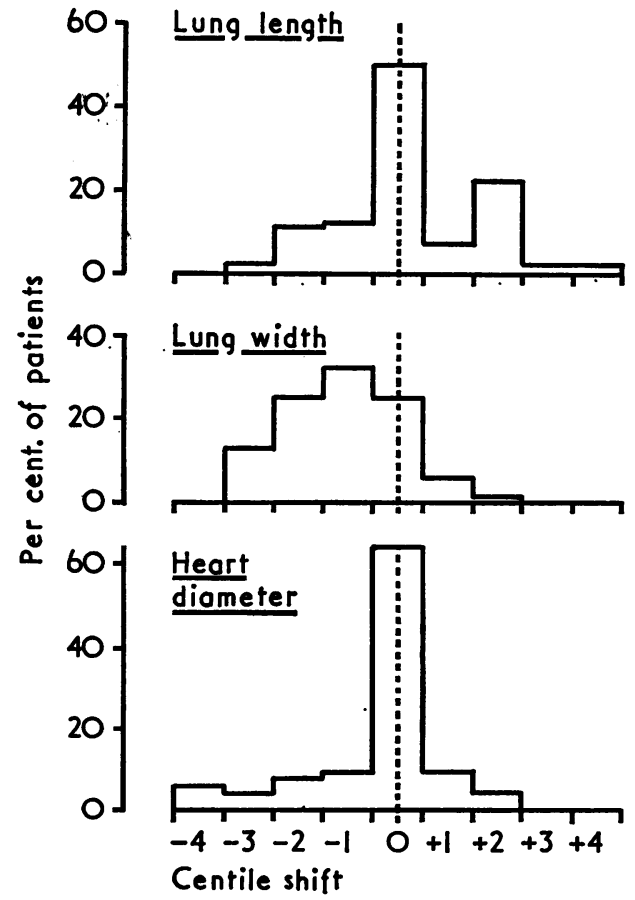

FIG. 4. Change in radiographic lung measurement during the 4-9 years follow-up (70 patients). The changes are expressed as shift from initial centile line $(+)$ or $(-)$.

Lung length: lung width ratio In normal children at 12 years this is between 0.8 and 0.87 . In $15 \%$ of the patients this ratio was greater than 0.9 and in half of these patients this increase in ratio was due to a decrease in lung width and not to increasing lung length. In $40 \%$ of patients the ratio was less than $0 \cdot 8$.

The change which was observed during the period of follow-up in the majority of patients was a decrease in lung width centile without a proportionate change in lung length or change in heart diameter centile.

\section{RELATION BETWEEN CHANGES IN VENTILATORY CAPACITY, CLINICAL STATUS, AND RADIOGRAPHIC LUNG MEASUREMENT}

Eleven of 76 patients died during the follow-up period. Only two of the 59 who had serial measurements of ventilatory capacity died. The changes in ventilatory capacity and in clinical and radiological status were assessed in these 57 remaining patients as follows:

REMAINING SYMPTOM FREE (15 patients) Initially, the FVC and $F E V_{1}$ values were within the predicted normal for height and these increased with increasing height in a near normal manner. These patients were all without productive cough or other respiratory symptoms and chest radiographs were normal or showed minimal tramline shadows (group I). These findings persisted during follow-up.

ATYPICAL SIGNS (11 patients) Initially, the FVC and $\mathrm{FEV}_{1}$ values were within the predicted normal 
for height and the patients in group I as described above. It was noted that with increasing height the FVC and $F E V_{1}$ did not increase as expected although there had been no acute clinical illness. The patient's clinical progress was not entirely satisfactory ; some had complained of intermittent productive cough and others of more frequent episodes of non-productive cough; some had an increased respiratory rate at rest. Changes in the chest radiograph, if present. consisted of an alteration in the tram-line shadows, but not that usually seen with increasing pulmonary infection in cystic fibrosis. These patients did not fit into group II or III as described but it was not possible to leave them in group I.

MINIMAL SIGNS AND SYMPTOMS (20 patients) Initially, the FVC and $\mathrm{FEV}_{1}$ values were below the predicted normal for height in the majority of these patients. These values increased at a slower rate than normal, as might be expected from the clinical progress. The patients were either initially symptom free with normal chest radiographs (group I) but later developed productive cough and localized radiological changes (collapse and/or consolidation or localized bronchiectasis-group II) or the patients initially had these clinical and radiological findings which persisted unchanged during followup.

PERSISTING SEVERE SIGNS AND SYMPTOMS (11 patients) Initially, the FVC and $\mathrm{FEV}_{1}$ values were below the normal predicted for height and increased little or diminished during follow-up. These patients initially were either group II as described above and progressed to severe pulmonary infection with generalized changes in the chest radiograph (group III) or were in group III throughout the study.
VENTILATORY CAPACITY The changes in the FVC and $F E V_{1}$ have been expressed as millilitres change per centimetre of height increase. The results are compared with the expected change in normal children (Table II).

The patients who had remained symptom free had an increase in FVC and $\mathrm{FEV}_{1}$ (as millilitres per centimetre of height increase) similar to that expected in normal children. The increases were least in those patients who initially were the most severely affected. Those patients judged to have atypical signs had an increase in these lung measurements only slightly greater than those that occurred in the most severely affected patients.

HEIGHT The rate of height increase was greatest in those patients who remained without symptoms and least in those who were severely affected during the follow-up period. The growth of the patients judged to have atypical signs was approximately midway between the two.

RADIOGRAPHIC LUNG MEASUREMENTS The changes which have occurred have been expressed as an increase or decrease from the initial centile line (Table III).

LUNG LENGTH Sixty-four per cent of the patients with atypical signs did not have any change in lung length centile. This percentage was higher than in the other groups described $(40 \% ; 46 \%$; $36 \%)$.

LUNG WIDTH All the patients with atypical signs had a decrease in lung width centile. Seventy-one per cent of the patients who had persisting severe signs and symptoms also showed a decrease of this centile.

HEART DIAMETER Eighty-two per cent of the

T A B LE I I

INCREASE IN HEIGHT AND CHANGE IN FEV AND FVC VOLUMES PER CENTIMETRE OF GROWTH RELATED TO CLINICAL CHANGE DURING FOLLOW-UP

\begin{tabular}{|c|c|c|c|c|c|}
\hline & & $\begin{array}{c}\text { Symptom } \\
\text { Free } \\
\text { (15 patients) }\end{array}$ & $\begin{array}{l}\text { Atypical Signs } \\
\text { and Symptoms } \\
\text { (11 patients) }\end{array}$ & $\begin{array}{l}\text { Minimal Signs } \\
\text { and Symptoms } \\
\text { (20 patients) }\end{array}$ & $\begin{array}{l}\text { Severe Signs } \\
\text { and Symptoms } \\
\text { (11 patients) }\end{array}$ \\
\hline \multicolumn{2}{|c|}{$\begin{array}{l}\text { Average follow-up with measurement of } \\
\text { FEV /FVC (yr) }\end{array}$} & & & & \\
\hline $\begin{array}{l}\text { Height increase }(\mathrm{cm}) \\
\text { FEV increase ( } \mathrm{ml} / \mathrm{cm} \text { of growth) } \\
\text { FVC increase ( } \mathrm{ml} / \mathrm{cm} \text { of growth) }\end{array}$ & $\begin{array}{l}\text { Mean } \\
\text { SD } \\
\text { SE } \\
\text { Mean } \\
\text { SD } \\
\text { SE } \\
\text { Mean } \\
\text { SD } \\
\text { SE }\end{array}$ & $\begin{array}{r}25 \cdot 5 \\
7 \cdot 8 \\
2 \cdot 0 \\
29 \cdot 4 \\
14 \cdot 8 \\
3 \cdot 8 \\
40 \cdot 3 \\
15 \cdot 2 \\
3 \cdot 9\end{array}$ & $\begin{array}{r}29 \cdot 5 \\
5 \cdot 8 \\
1 \cdot 8 \\
9 \cdot 4 \\
8 \cdot 1 \\
2 \cdot 5 \\
15 \cdot 2 \\
13 \cdot 7 \\
4 \cdot 2\end{array}$ & $\begin{array}{r}25 \cdot 3 \\
6 \cdot 0 \\
1 \cdot 3 \\
17 \cdot 3 \\
15 \cdot 1 \\
3 \cdot 4 \\
22 \cdot 5 \\
13 \cdot 1 \\
2 \cdot 9\end{array}$ & $\begin{array}{r}23 \cdot 5 \\
6 \cdot 0 \\
1 \cdot 8 \\
3 \cdot 1 \\
18 \cdot 7 \\
4 \cdot 1 \\
10 \cdot 4 \\
9 \cdot 8 \\
3 \cdot 0\end{array}$ \\
\hline
\end{tabular}

(Normal increase of FEV and FVC per $\mathrm{cm}$ of growth would be 36 and $42 \mathrm{ml}$-estimated from normal values of Strang (1959).

The differences in values for the FVC in patients remaining symptom free compared with those with atypical signs and those with severe signs were highly significant $(P<0.001)$. The differences in values for the FEV between patients remaining symptom free and those with atypical signs were highly significant $(P<0.001)$ and between the symptom free and those with severe signs the difference was significant $(P<0.005)$. 
T A B L E III

CHANGE IN LUNG CENTILES COMPARED WITH PRO\begin{tabular}{l|c|c|c|c}
\multicolumn{3}{c}{ GRESSION OF PULMONARY INVOLVEMENT } \\
\hline & $\begin{array}{c}\text { Symptom } \\
\text { Free } \\
\left(\begin{array}{c}\% \\
\text { of } \\
\text { patients) }\end{array}\right.\end{array}$ & $\begin{array}{c}\text { Atypical } \\
\text { Signs and } \\
\text { Symptoms } \\
\text { (\% of } \\
11 \\
\text { patients) }\end{array}$ & $\begin{array}{c}\text { Minimal } \\
\text { Signs and } \\
\text { Symptoms } \\
\text { (\% of } \\
20 \\
\text { patients) }\end{array}$ & $\begin{array}{c}\text { Severe } \\
\text { Signs and } \\
\text { Symptoms } \\
\text { (\% of } \\
11 \\
\text { patients) }\end{array}$ \\
\hline $\begin{array}{l}\text { Length centile: } \\
\text { Same }\end{array}$ & 40 & 64 & 40 & 36 \\
\pm & 33 & 18 & 25 & 36 \\
Width centile: & 27 & 18 & 35 & 28 \\
Same & 46 & 0 & 30 & 24 \\
\pm & 13 & 0 & 10 & 5 \\
Heart diameter & 41 & 100 & 60 & 71 \\
centile: & & & & \\
Same & 66 & 9 & 80 & 59 \\
\pm & 27 & 99 & 10 & 8 \\
- & 7 & 82 & 10 & 33 \\
\hline
\end{tabular}

patients with atypical signs had a reduction of heart diameter centile while only $33 \%$ with severe signs and symptoms showed this change. A larger proportion of the patients who had remained free of symptoms had an increase in heart diameter centile than in the other groups.

Comparison of the degree of change in the lung width and heart diameter centiles of the patients with atypical signs compared with the whole series showed that six of these 11 patients and only two other patients had a reduction of lung width of three or more centiles. Heart diameter was reduced to a similar degree in six of these 11 patients and in only three other patients (Fig. 5).

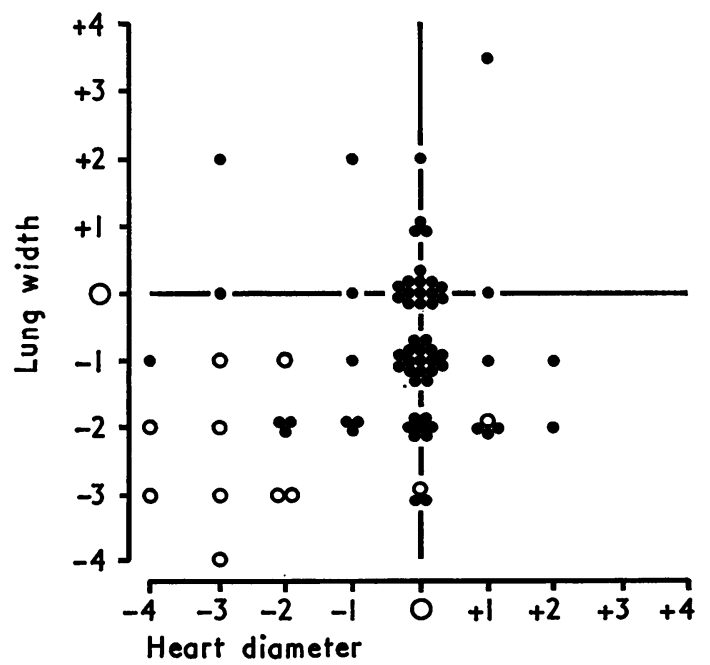

FIG. 5. Changes in lung width centile plotted against change in heart diameter centile in 76 patients (0 represents patient with 'atypical signs').
ASSESSMENT OF THE LATERAL VIEW RADIOGRAPHS

At the end of the study lateral view radiographs were available for 46 of the 76 patients. No abnormality was recognized in $57 \%$ of these radiographs (26 patients). The position and curve of the diaphragm were considered normal in all the radiographs examined. In approximately $75 \%$ of the 20 lateral radiographs which were abnormal an increase in the size of the retrosternal transradiant space and some forward bowing of the sternum was seen $(70 \%$ and $80 \%$ respectively). In only $15 \%$ was an increase in the retrosternal space present in isolation, and in the same percentage an isolated sternal bowing was found. Kyphosis in excess of normal was recognized in $30 \%$ of the radiographs (7 of 20); in all but one of these films kyphosis was associated with sternal bowing (Table IV).

T A B LE I V

ASSESSMENT OF LATERAL VIEW RADIOGRAPHS OF 20 PATIENTS TO SHOW ASSOCIATION OF ABNORMAL FINDINGS

\begin{tabular}{ccc}
\hline $\begin{array}{c}\text { Increased Retrosternal } \\
\text { Space }\end{array}$ & Sternal Bowing & Kyphosis \\
\hline$*$ & & \\
\hline$*$ & $*$ & \\
\hline$*$ & $*$ \\
$*$ & $*$ & \\
$*$ & $*$ & \\
\hline$*$ & $*$ & $*$ \\
$*$ & $*$ & $*$ \\
\hline & $*$ & $*$ \\
\hline & $*$ & $*$ \\
\hline & $*$ & $*$ \\
\hline
\end{tabular}

LATERAL VIEW RADIOGRAPHS ASSESSED IN RELATION TO CHANGES IN VENTILATORY CAPACITY AND CLINICAL STATUS IN 39 PATIENTS (as described above) The lateral view radiographs of the 11 patients who remained free of signs and symptoms were normal. Normal lateral view radiographs were also found in $66 \%, 42 \%$, and $43 \%$ where signs and symptoms were atypical, minimal or persisting and severe respectively.

An increase in the retrosternal transradiant zone was present in the radiograph of only one patient with atypical signs but occurred in $33 \%$ (4 of 12 patients) with minimal signs and symptoms, and 
in $43 \%$ ( 3 of 7 patients) with persisting severe signs and symptoms.

Sternal bowing occurred less frequently in those patients with atypical signs than in those with the minimal or persisting severe signs where the incidence was approximately equal. Kyphosis was found in $33 \%$ with atypical signs and in $43 \%$ with severe signs and symptoms but was not present in any with minimal signs and symptoms (Table V).

\section{T A B LE V}

FINDINGS ON LATERAL VIEW RADIOGRAPHS COMPARED WITH CHANGES IN SIGNS AND SYMPTOMS

\begin{tabular}{|c|c|c|c|c|}
\hline & $\begin{array}{c}\text { No } \\
\text { Abnormality }\end{array}$ & $\begin{array}{l}\text { Increased } \\
\text { Retro- } \\
\text { sternal } \\
\text { Space }\end{array}$ & $\begin{array}{l}\text { Sternal } \\
\text { Bowing }\end{array}$ & Kyphosis \\
\hline $\begin{array}{l}\text { Remaining } \\
\text { symptom free } \\
\text { (11 patients) }\end{array}$ & $\begin{array}{l}* \\
* \\
* \\
* \\
* \\
* \\
* \\
* \\
* \\
*\end{array}$ & & & \\
\hline $\begin{array}{l}\text { Atypical signs } \\
\text { and symptoms } \\
\text { (9 patients) }\end{array}$ & $\begin{array}{l}* \\
* \\
* \\
* \\
*\end{array}$ & * & $*$ & * \\
\hline $\begin{array}{l}\text { Minimal signs } \\
\text { and symptoms } \\
\text { (12 patients) }\end{array}$ & $\begin{array}{l}* \\
* \\
* \\
*\end{array}$ & $\begin{array}{l}* \\
* \\
*\end{array}$ & $\begin{array}{l}* \\
* \\
* \\
* \\
*\end{array}$ & \\
\hline $\begin{array}{l}\text { Severe signs } \\
\text { and symptoms } \\
\text { (7 patients) }\end{array}$ & * & $\begin{array}{l}* \\
* \\
*\end{array}$ & $*$ & * \\
\hline
\end{tabular}

The lateral view radiographs were judged normal in approximately half of the patients who showed clinical and radiological deterioration. The earliest change is probably an increase in the retrosternal transradiant zone, this being followed by forward bowing of the sternum, usually associated with some kyphosis. In the group of patients with atypical signs, three of nine had kyphosis but the retrosternal transradiant zone was increased in only one of these three.
DISCUSSION

One of the earliest accounts of the radiological findings in cystic fibrosis was given by Neuhauser in 1946. He stated that there is an easily recognized picture of obstructive emphysema. The volume of the lungs is increased with flattening and depression of the diaphragm. Further descriptions have included increase in the anteroposterior diameter of the chest with bulging of the sternum anteriorly (Keats, 1955 ; di Sant'Agnese, 1955 ; White and Rowley, 1964). Many authors have referred to the presence of emphysema but have not described their criteria for this abnormality. Keats (1955) wrote that in children emphysema may manifest itself by an increase in anteroposterior diameter, increased width of the retrosternal space, flattening of the domes of the diaphragm, and diminished size of the cardiac shadow.

Centile charts for heart and lung growth as determined radiologically have been used in the present study to show the growth patterns in children with cystic fibrosis. Increase in lung length was not the invariable finding in the patients with severe pulmonary involvement although there was a trend towards increasing lung length with increasing age. Flattening of the diaphragm was not seen in any patient. An unexplained finding was that at 6 years of age $61 \%$ of the patients studied had a lung width centile greater than might have been expected in relation to their height centile. During an average follow-up of seven years this centile decreased so that finally $48 \%$ of the patients had lung width centiles less than expected. This was not associated with a proportionate increase in length. The lung length: lung width ratio was above 0.9 in only $15 \%$ of the patients at the age of 12 years and in half of these patients this increased ratio was due to a reduction in lung width rather than to an increase in lung length. This supports the finding that the width narrowed out of proportion to increasing length. This ratio was below the normal range in $40 \%$ of the patients, which would suggest that the lungs were not voluminous. The majority of the patients studied did not have abdominal distension and gastrointestinal symptoms which might cause flaring of the lower rib cage or raising of the diaphragm. During the period of follow-up the lung area centile as measured on PA films increased in only $8 \%$ and decreased in $30 \%$ of the patients. These findings are against there being widespread panacinar emphysema with air trapping and are thus in keeping with previous phy- 


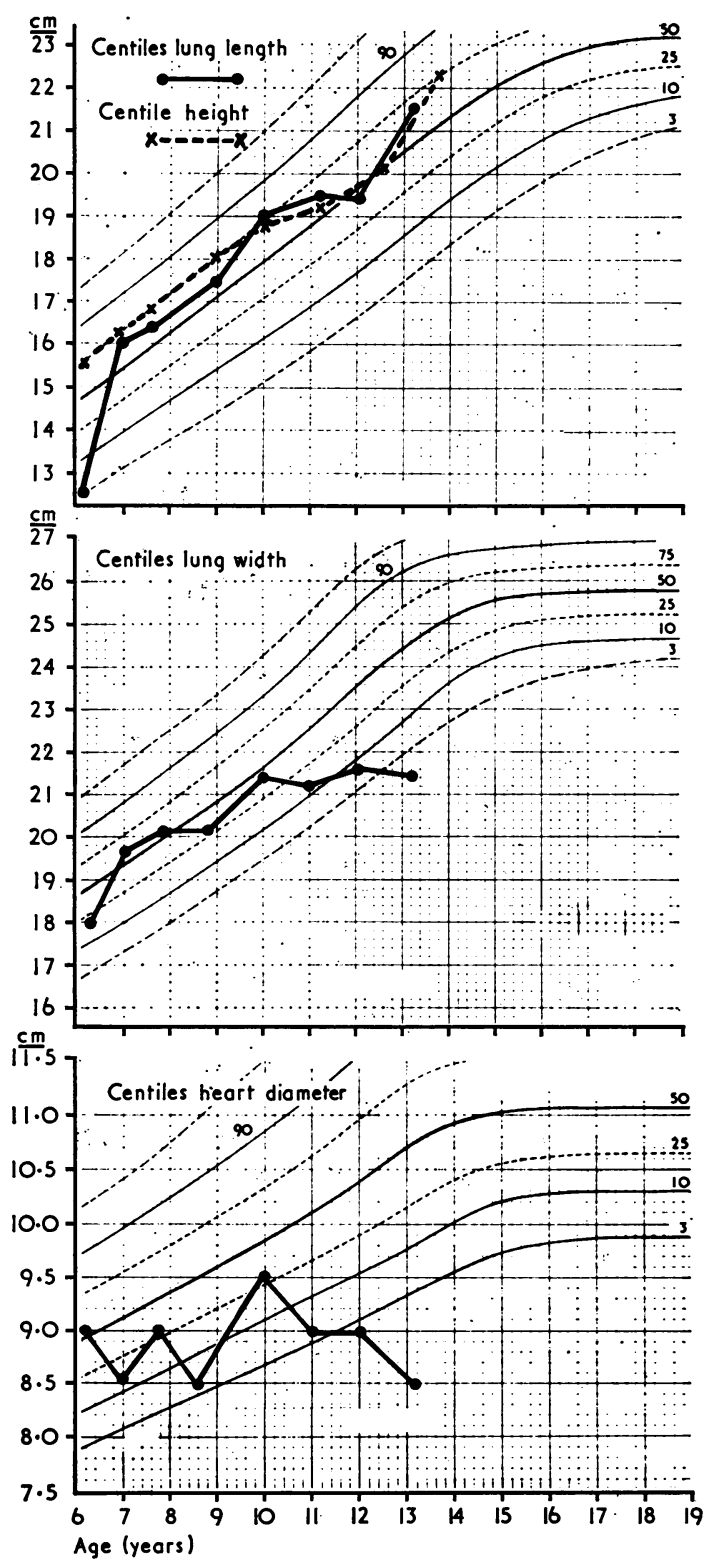

FIG. 6. Group I patient who developed 'atypical signs', the FVC not increasing with increasing height. Centile charts show height and lung length centiles maintained. Lung width and heart diameter centiles decreased.

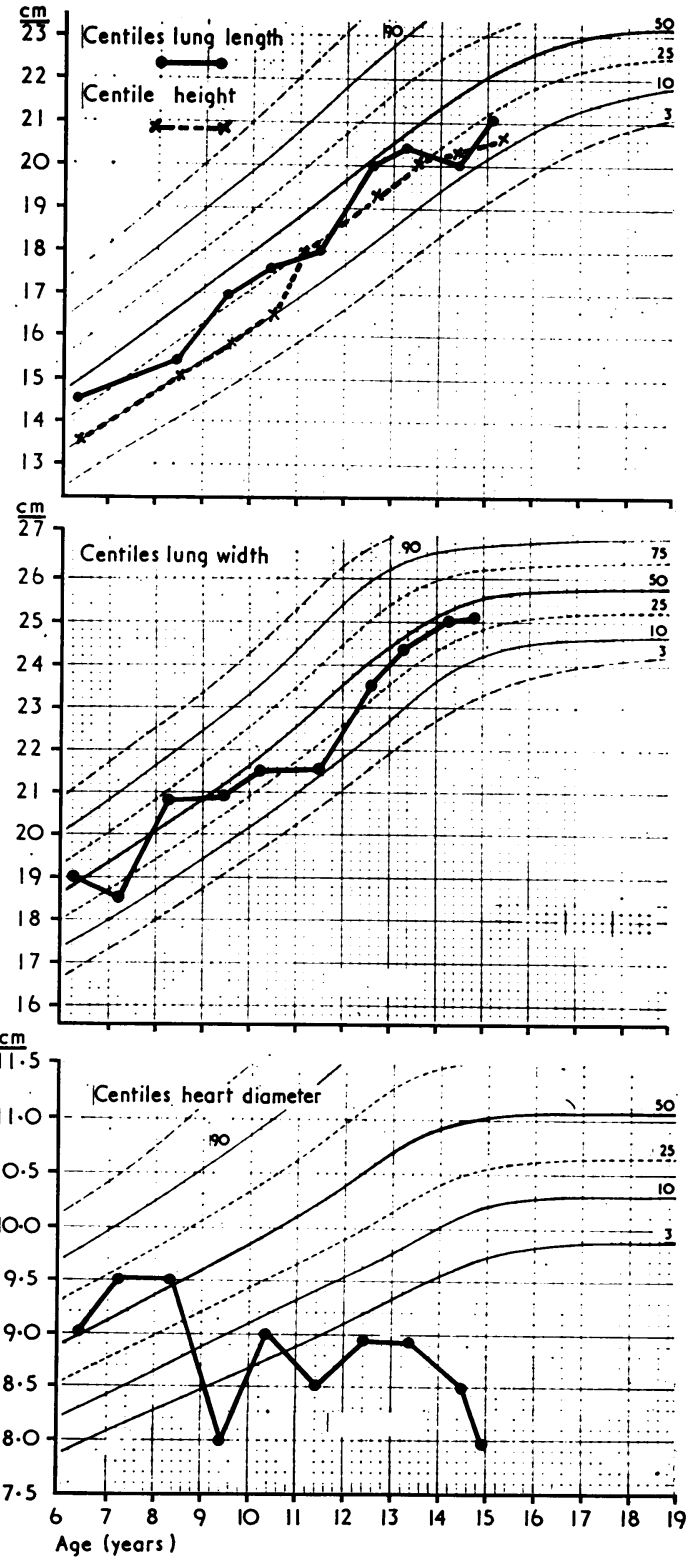

FIG. 7. Patient initially at 6 years of age in group II and who by 10 years had progressed to group III and died at $15 \frac{1}{2}$ years. Centiles for height, lung length, and lung width show little change, but heart diameter centile decreased. 
siological studies. Doershuk and Matthews (1968), Featherby et al. (1969), and Godfrey and Mearns (1971) found that only a few children with cystic fibrosis have an increased total lung capacity. The present study relates to findings after 5 years of age ; earlier descriptions of the radiological findings in this disease probably relate to infancy and very early childhood, as few patients survived beyond 5 years of age at that time. This may account for some of the differences from the present study.

Another finding in the present study was that the heart shadow tended to be narrow and with increasing age or severity of disease this trend continued (Figs. 6 and 7). Royce (1955) found at necropsy that the heart in cases of cystic fibrosis was small in bulk but above normal in weight. The diminished size of the cardiac shadow noted on radiographs has been attributed to emphysema (Keats, 1955; Caffey ; 1967). The present study demonstrates that few patients increased their heart diameter centile and that this centile tended to be less than might be expected in comparison with the lung length centile even in patients with minimal pulmonary involvement. This suggests that the primary cause may lie in the cardiovascular system rather than in the lungs.

From this study a group of patients are identified who have a more marked decrease in lung width and heart diameter than would have been expected from the clinical evidence of lung disease. The lateral view radiographs do not show any flattening of the diaphragm or other signs of overdistension of the lungs. Initially these patients were symptom-free and had values for $\mathrm{FEV}_{1}$ and FVC within the normal range for height. They were first identified as a group when serial measurements of vital capacity failed to increase in proportion to height (Fig. 8).

The significance of these findings remains to be determined. Possible causes include insidious infection, blocking of small peripheral bronchi with mucus, the production of which may have been triggered by an unknown factor, or impaired lung growth in early life so that there is now a relative hypoplasia. Increase in the number of alveoli occurs in the first eight years of life, after which there is only an increase in size. In cystic fibrosis there may be several factors which influence the total number of alveoli present when the lungs are fully developed. The lung centile charts may help to determine whether the lungs develop in a normal manner or whether there is a disturbance of intrinsic growth.

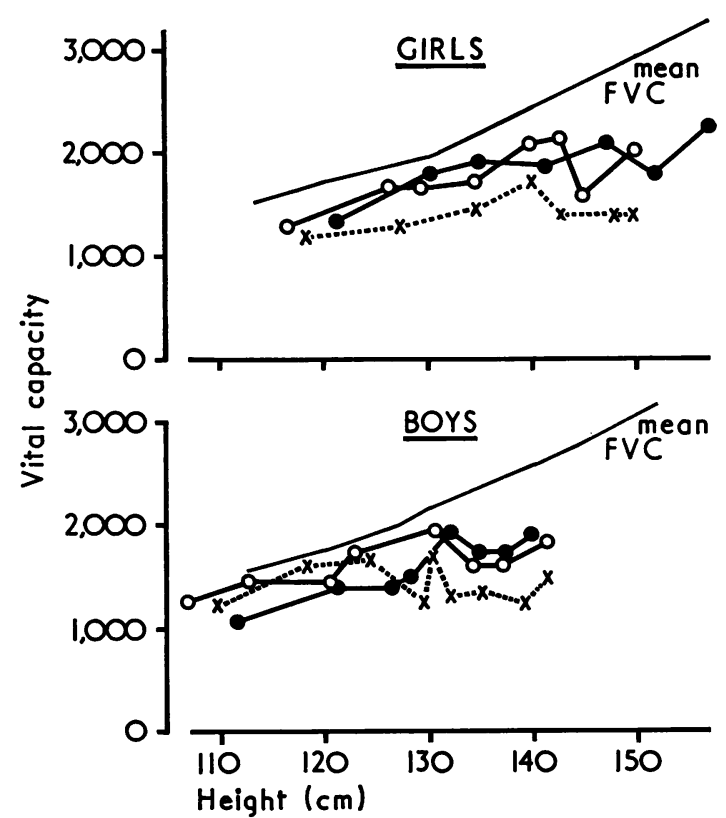

FIG. 8. Failure to increase FVC with increasing height in patients with 'atypical signs' (continuous line normal expected value).

The authors thank Dr. D. G. Shaw, radiologist to the Queen Elizabeth Hospital, for allowing them to study the radiographs of these patients and are grateful to Professor Lynne Reid for her help and encouragement.

Margaret B. Mearns is in receipt of a grant from the Cystic Fibrosis Trust.

\section{REFERENCES}

Bernstein, L., D'Silva, J. L., and Mendel, D. (1952). The effect of the rate of breathing on the maximum breathing capacity determined with a new spirometer. Thorax, 7 , 255.

Caffey, J. (1967). Pediatric X-ray Diagnosis, 5th ed., p. 285. Year Book Medical Publishers, Chicago.

Doershuk, C. F., and Matthews, L. W. (1968). Cystic fibrosis and obstructive pulmonary disease. In: $A m b u-$ latory Pediatrics. p. 707, edited by M. Green and R. J. Haggerty. W. B. Saunders, Philadelphia.

di Sant'Agnese, P. A. (1955). The pulmonary manifestations of fibrocystic disease of the pancreas. Diseases of the Chest, 27, 654.

Featherby, E. A., Weng, T-R., Crozier, D. N., Duic, A., Reilly, B. J., and Levison, H. (1969). Dynamic and static lung volumes, blood-gas tensions and diffusing capacity in patients with cystic fibrosis. In Proceedings of 5 th International Cystic Fibrosis Conference, Cambridge, p. 232, edited by D. Lawson. Cystic Fibrosis Trust, London. 
Godfrey, S., and Mearns, M. (1971). Pulmonary function and response to exercise in cystic fibrosis. Archives of Diseases in Childhood, 46, 144.

Keats, T. E. (1955). Generalized pulmonary emphysema as an isolated manifestation of early cystic fibrosis of the pancreas. Radiology, 65, 223.

Neuhauser, E. B. D. (1946). Roentgen changes associated with pancreatic insufficiency in early life. Radiology, 46, 319.

Royce, S. W. (1955). Cardiac and pulmonary complications in fibrocystic disease of the pancreas. (Discussion). In Reports of the 18th Ross Pediatric Research Conference, p. 79.

Simon, G., Connolly, N., Littlejohns, D. W., and McAllen, M. (1973). Radiological abnormalities in children with asthma. Thorax, (In press).
_, Reid, L., Tanner, J. M., Goldstein, H., and Benjamin, B. (1972). Growth of radiologically determined heart $\frac{\mathcal{S}}{\partial}$ diameter, lung width, and lung length from 5-19 years, $\mathbb{D}$ with standards for clinical use. Archives of Diseases in
Childhood, 47,373 .

Strang, L. B. (1959). The ventilatory capacity of normal children. Thorax, 14, 305.

Tanner, J. M., Whitehouse, R. H., and Takaishi, M. (1966). Standards from birth to maturity for height, weight, $\vec{x}$ height velocity, and weight velocity. British children, i 1965. Part I. Archives of Diseases in Childhood, 41, 454.

White, H., and Rowley, W. F. (1964). Cystic fibrosis of the pancreas. Clinical and roentgenographic manifestations. Pediatric Clinics of North America, 11, No. 1, p. 139. 